Short note

\title{
One- and two-dimensional models are equally effective in monitoring the crust's thermal response to advection by large-scale thrusting during orogenesis
}

\author{
J. Alcock ${ }^{\mathrm{a}, *}$, J.R. Martínez Catalán ${ }^{\mathrm{b}}$, R. Arenas ${ }^{\mathrm{c}}$ \\ ${ }^{a}$ Department of Geosciences, Abington College, Penn State University, Abington, PA 19001, USA \\ b Departamento de Geología, Universidad de Salamanca, 37008 Salamanca, Spain \\ 'Departamento de Petrología y Geoquímica e Instituto de Geología Económica [CSIC], Universidad Complutense, 28040 Madrid, Spain
}

Keywords:

Thermal modeling

One dimensional

2-dimensional

Finite difference

Orogeny

Thermal modeling has been used for several decades to explore the thermal effects of crustal thickening associated with orogenic events (England and Thompson, 1984; Thompson and England, 1984; Peacock, 1989) and more recently to use the thermal models to evaluate potential $P-T-t$ paths of specific terrains that had been proposed to explain data obtained from structural, metamorphic, and geochronological studies (e.g., Burg et al., 2004; Gerya et al., 2004; Alcock et al., 2009). Originally, thermal models were restricted to one dimension (1-D) but with the advent of faster and more accessible computing, two-dimensional (2-D) models that include advection of heat through tectonic and magmatic activity have become popular (Peacock, 1989; Gerya et al., 2004). The added complexity of 2-D models, especially those including advections, can lead to a significant increase in computing time and may act to obscure the interpretation of variation in model outcomes that result from experimentation with the values of model parameters. The more transparent 1-D model typically facilitates the researcher's ability to conduct experiments and to evaluate the effect changing variables have on model results.

\footnotetext{
* Corresponding author.

E-mail address: jea4@psu.edu (J. Alcock).
}

In 2007 we submitted a paper presenting results of 1-D thermal models of the thermo-tectonic history of the Lugo dome in northwestern Spain (Alcock et al., 2009). The dome is a N-S, 140-km-long and 35-km-wide structure developed at the internal parts of the Mondoñedo nappe, a set of kilometric-scale recumbent folds floored by a thrust fault. Variscan metamorphism reached the sillimanite-orthoclase zone and partial melting occurred in the dome's core, where the relative autochthon of the Mondoñedo nappe is exposed in tectonic windows. Voluminous Variscan granitoids indicate significant crustal melting at various levels. Recent reviews on the evolution of the Mondoñedo nappe are presented in Arenas and Martínez Catalán (2003) and Martínez Catalán et al. (2003).

We intentionally chose to use 1-D models because they allowed us to conduct experiments that evaluated the effects of a variety of parameters on the thermal history of the dome. However, several reviewers of our paper criticized the approach, arguing that the 1-D models were significantly less accurate than $2-D$, and so the results of the experiments were not valid. In response to these reviews we decided to test that thesis by constructing a 2-D model and comparing the results obtained with those produced by our previous work in 1-D.

In both sets of models, the model crust is subjected to a series of deformations that include homogeneous thickening and thrusting that replace a portion of the crust while simultaneously 


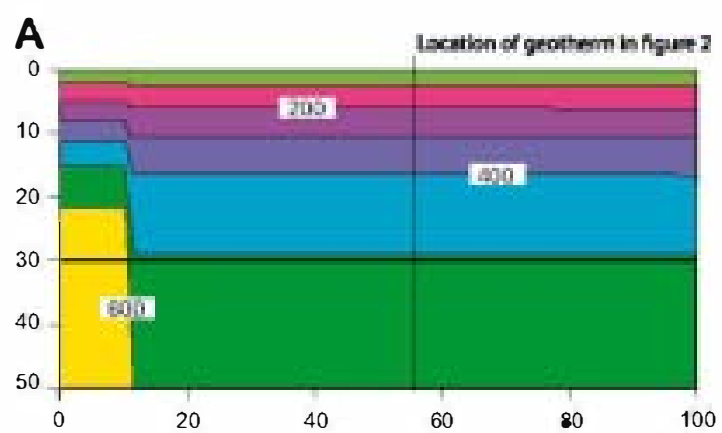

B

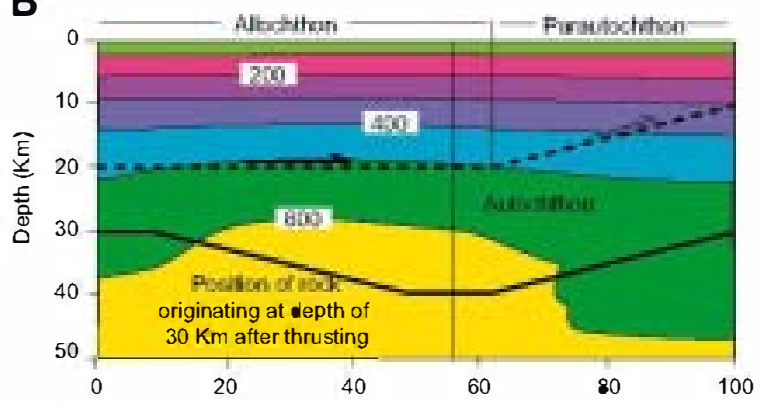

C

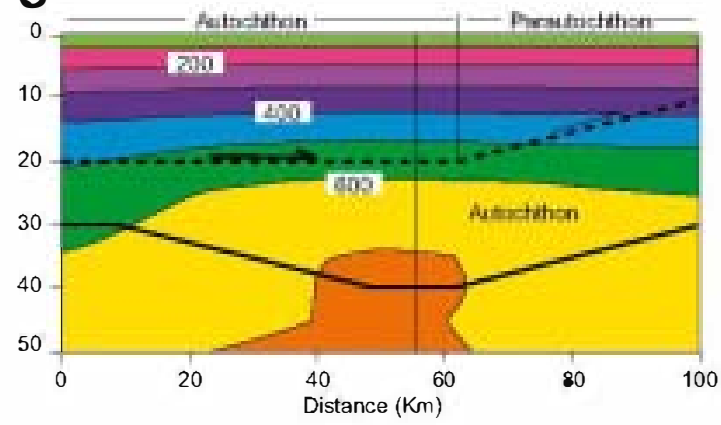

Fig. 1. Results from 2-D model after initial homogeneous thickening and at the beginning of thrusting (A), at $4 \mathrm{Ma}(\mathrm{B})$, and at $14 \mathrm{Ma}(\mathrm{C})$ after a $6 \mathrm{Ma}$ period of thrusting ends are presented as crustal cross-sections with isotherms. Source of allochthon experienced $10 \mathrm{~km}$ of erosion prior to thrusting, which is the cause of the temperature difference at distance $10 \mathrm{~km}$ in (A). Trace of the thrust surface in the model is shown with a dashed line. The effect of the thrust on the location of a rock at a depth of $30 \mathrm{~km}$ before thrusting is shown with a heavy solid line.

thickening the crust to model the emplacement of the Mondoñedo nappe. Thickening is followed by thermal relaxation and then by homogeneous thinning that returns the Moho to a depth $\approx 40 \mathrm{~km}$. Results from the two methods are illustrated in Figs. 1 and 2. Homogeneous thickening and thinning in both models are accomplished by using a natural strain parameter to calculate incremental vertical movement of model nodes. A listing of representative parameters used in the experiment is presented in Table 1.

The treatment of thrusting is the most important difference between the 1-D and the 2-D models because instantaneous emplacement is used in 1-D while emplacement by incremental movement is used in the 2-D model. In 2-D the thrust is treated as moving along a ramp sloped at $14^{*}$ and then along a flat where the 20 -km-thick thrust sheet replaces $10 \mathrm{~km}$ of autochthon. The slope is arbitrary as it was chosen to allow incremental motion by moving four nodes horizontally for each node of vertical movement, but the relatively shallow dip of the ramp is reasonable. A horizontal velocity of $1 \mathrm{~cm}$ per year of the thrust is achieved in the model as a 4-km-long step resulting in $1 \mathrm{~km}$ or one node of vertical displacement each $0.4 \mathrm{Ma}$. Thrusting continues for 6.0 Ma, leading to a total horizontal displacement of $60 \mathrm{~km}$.

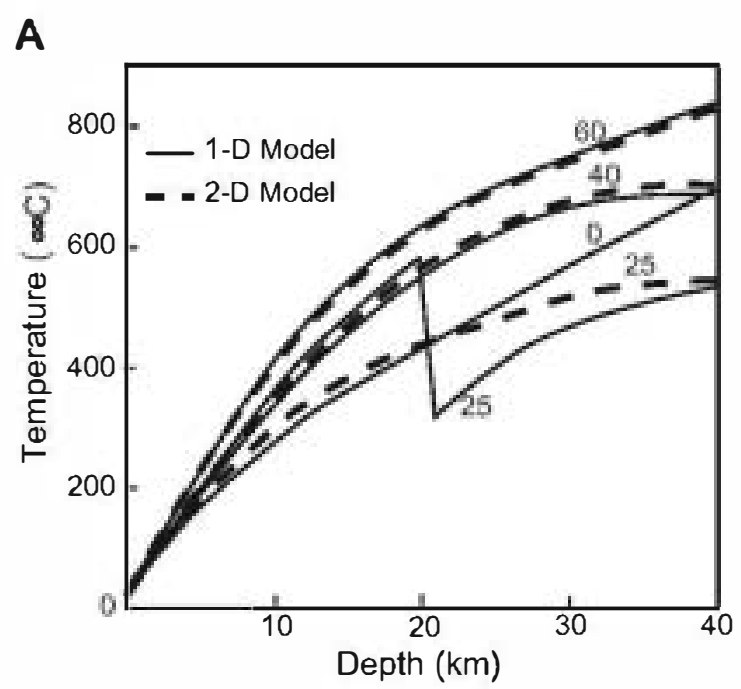

B
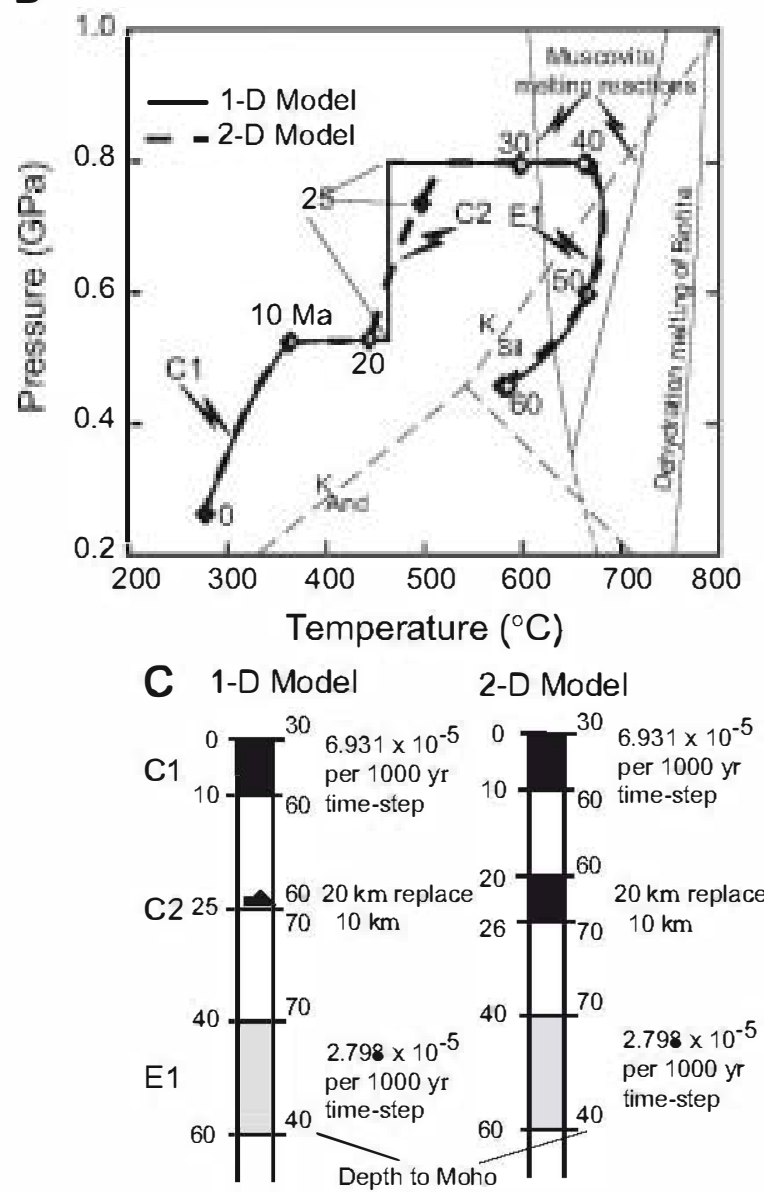

Fig. 2. A comparison of 1-D and 2-D models of the thermal history of the Lugo dome that includes homogeneous thickening followed by thrusting and eventual homogeneous thinning. (A) Results are presented as crustal geotherms. Sawtooth geotherm produced by instantaneous thickening has been smoothed and both geotherms are similar within $15 \mathrm{Ma}$ of thrusting. (B) Models are compared by tracing the history of a particular node that originates at a depth of $10 \mathrm{~km}$ and resides $10 \mathrm{~km}$ beneath the thrust after homogeneous thickening and thrusting. The thermal history of this node is essentially independent of the model used. (C) A comparison of the two models showing stages of thickening and thinning of the crust in response to compression and erosion.

Results of the 1-D and 2-D models are compared in Fig. $2 \mathrm{~A}$ and $\mathbf{B}$. As can be seen the $P-T-t$ paths are nearly indistinguishable with the exception of the unrealistic instantaneous change 


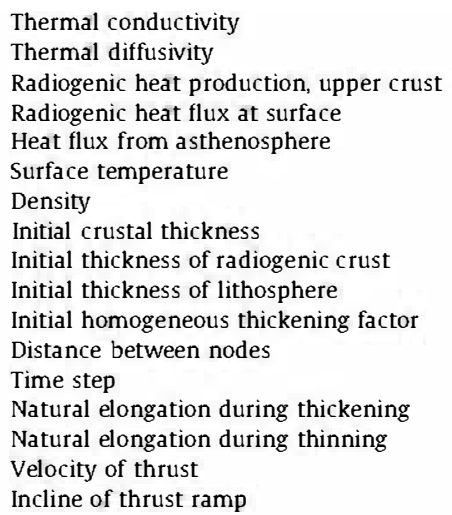

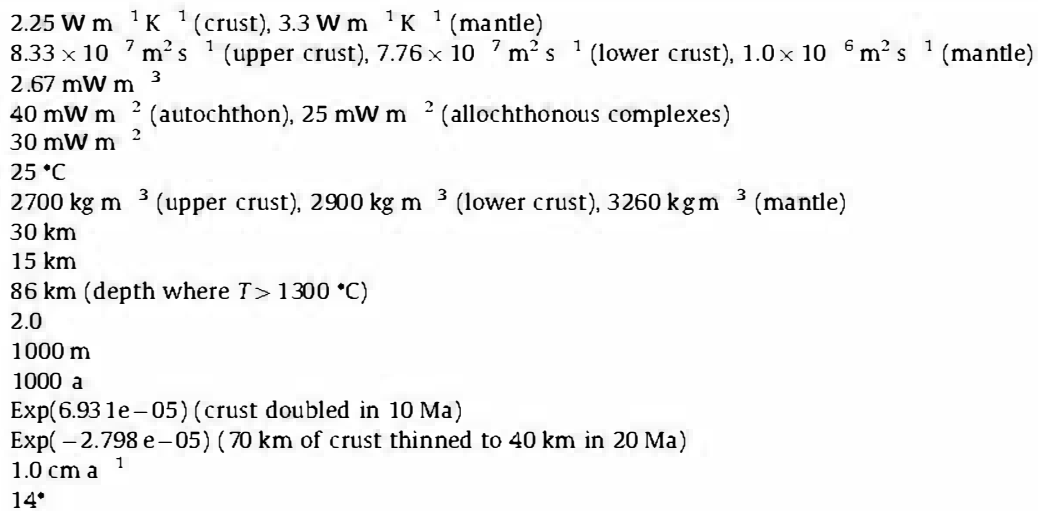

in pressure that models thrust emplacement in 1-D. We find the similarity of model results to be impressive and conclude that the results of the 1-D model are as accurate as those obtained using 2-D methods and do not think that one could distinguish between the two if one were attempting to compare the results to an actual rock record. We recognize that multidimensional models are useful when horizontal temperature gradients are similar to vertical gradients. However, when considering advective heating by thrusting, the horizontal heat transfer will be small relative to the vertical flux and so does not need to be considered in the model. We feel that there are significant advantages to 1-D models derived from their relative simplicity and that 1-D models should not be dismissed as ineffective simply because we have the ability to create more complex representations of the geologic system.

\section{Acknowledgments}

We thank the reviewers T. Gerya and J.C. Mareschal, for their thoughtful comments on an earlier version of this paper. Research presented was supported by Spanish projects CGL2004-0463CO2/BTE and CGL2007-65338-C02/BTE (Ministerio de Educación y Ciencia, Dirección General de Investigación).

\section{References}

Alcock, J.E., Martínez Catalán, J.R, Arenas, R, Diez Montes, A., 2009. Use of thermal modeling to assess the tectono-metamorphic history of the Lugo and Sanabria Domes, Northwest Iberia. Bulletin de la Societe Geologique de France 180, 85-103.

Arenas, R, Martínez Catalán, J.R, 2003. Low-P metamorphism following a Barrovian-type evolution. Complex tectonic controls for a common transition, as deduced in the Mondoñedo thrust sheet (NW Iberian Massif). Tectonophysics $365,143-164$.

Burg, J.-P., Kaus, B.J.P., Podladchikov, Y.Y., 2004. Dome structures in collision orogens: mechanical investigation of the gravity/compression interplay. In: Whitney, D.L., Teyssier, C., Siddoway, C.S. (Eds.), G neiss Domes in Orogeny, Geological Society of America Special Paper, vol. 380, pp. 47-66.

England, P.C., Thompson, A.B., 1984. Pressure-temperature-time paths of regional metamorphism I. Heat transfer during the evolution of regions of thickened continental crust. Journal of Petrology 25, 894-928.

Gerya, T.V., Perchuk, L.L, Maresch, W.V., Willner, A.P., 2004. Inherent gravitational instability of hot continental crust: implications for doming and diapirism in granulite facies terrains. In: Whimey, D.L., Teyssier, C., Siddoway, C.S. (Eds.), Gneiss Domes in Orogeny, Geological Society of America Special Paper, vol. 380 , pp. 97-1 15.

Martínez Catalán, J.R, Arenas, R, Díez Balda, M.A., 2003. Large extensional structures developed during emplacement of a crystalline thrust sheet: the Mondoñedo nappe (NW Spain). Journal of Structural Geology 25, 1815-1839.

Peacock, S.M., 1989. Thermal modeling of metamorphic-pressure-temperaturetime paths. In: Spear, F.S., Peacock, S.M. (Eds.), Metamorphic PressureTemperature-Time Paths, American Geophysical Union, Short Course in Geology, vol. 7, pp. 57-102.

Thompson, A.B., England, P.C., 1984. Pressure-temperature-time paths of regional metamorphism. II. Their inference and interpretation using mineral assemblages in metamorphic rocks. Journal of Petrology 25, 929-955. 